Check for updates

Cite this: RSC Adv., 2019, 9, 15941

Received 4th April 2019

Accepted 10th May 2019

DOI: 10.1039/c9ra02546d

rsc.li/rsc-advances

\section{Preparation of sulfonated ordered mesoporous carbon catalyst and its catalytic performance for esterification of free fatty acids in waste cooking oils $\dagger$}

\begin{abstract}
Sun $\mathrm{Na}^{\text {ab }}$ Zhang Minhua, (D) ab Dong Xiuqin ${ }^{\mathrm{ab}}$ and Wang Lingtao (D) *ab
Sulfonated ordered mesoporous carbon $\left(\mathrm{SO}_{3} \mathrm{H}-\mathrm{OMC}\right)$ solid acid catalysts from sucrose were prepared using hard-template method, and their catalytic performance as well as the deactivation mechanism for esterification of free fatty acids (FFAs) in waste cooking oils (WCOs) were evaluated. Effects of sulfonation time, sulfonation temperature and hard template structure type for the textural properties and acid properties of $\mathrm{SO}_{3} \mathrm{H}-\mathrm{OMC}$ were systematically investigated by $\mathrm{N}_{2}$ adsorption-desorption, FT-IR, $\mathrm{NH}_{3}-\mathrm{TPD}, \mathrm{TEM}$ and strong acid density analysis. The results indicated that, $\mathrm{SO}_{3} \mathrm{H}-\mathrm{OMC}(\mathrm{s})-6-160$ catalyst, which was prepared by using SBA-15 as hard template at sulfonation time of $6 \mathrm{~h}$ and sulfonation temperature of $160{ }^{\circ} \mathrm{C}$, had well-ordered mesoporous structure and high $-\mathrm{SO}_{3} \mathrm{H}$ groups density (2.32 mmo g ${ }^{-1}$ ). Compared with $\mathrm{SO}_{3} \mathrm{H}-\mathrm{APC}-6-160$ catalyst, cation-exchange resin $\mathrm{D} 072$ and $\mathrm{SO}_{3} \mathrm{H}-$ OMC(k)-6-160 catalyst, it was found that the $\mathrm{SO}_{3} \mathrm{H}-\mathrm{OMC}(\mathrm{s})-6-160$ catalyst exhibited highest activity (FFAs conversion was $93.8 \%$ ) and good stability for the FFAs esterification, attributed to its 2D-hexagonal channels and hydrophobic surface. The $-\mathrm{SO}_{3} \mathrm{H}$ groups being leached out of $\mathrm{SO}_{3} \mathrm{H}$-OMC catalysts into the liquid phase (especially methanol) would be the main reason causing catalyst deactivation.
\end{abstract}

\section{Introduction}

Since the increasing price of petroleum and severe environmental pollutions of using fossil energy, ${ }^{1-3}$ biodiesel (fatty acids methyl esters, FAME), as a promising eco-friendly alternative fuel to replace traditional fuels, has drawn extensive attention for its biodegradability, nontoxicity and favorable combustion property. ${ }^{4}$

However, due to the expenses of the raw materials like vegetable oil and animal fats are the main contributor to the cost of biodiesel production, biodiesel has not been widely promoted worldwide. ${ }^{5-7}$ In order to utilize economical raw materials, cheaply available waste cooking oils (WCOs) reused from restaurants and food plants are used., ${ }^{\mathbf{8} 9}$ But the large numbers of free fatty acids (FFAs) existing in the WCOs will be consumed via the saponification reaction in the presence of alkaline catalyst, which makes it ineffective to remain in onestep trans-esterification to biodiesel production. Thus the preesterification of FFAs with methanol before normal transesterification should be carried out for the feedstock of high

${ }^{a}$ Key Laboratory for Green Chemical Technology of Ministry of Education, R\&D Center for Petrochemical Technology, Tianjin University, Tianjin 300072, China. E-mail: ltwang@tju.edu.cn; Fax: +86-22-27406119; Tel: +86-22-27406119

${ }^{b}$ Collaborative Innovation Center of Chemical Science and Engineering, Tianjin, 300072, China

$\dagger$ Electronic supplementary information (ESI) available. See DOI: 10.1039/c9ra02546d acid value. ${ }^{\mathbf{1 0 - 1 3}}$ Generally, homogenous sulfuric acid, which is relatively cheap, exhibits high catalytic activity in the preesterification of FFAs, but it will lead to serious equipment corrosion, environment pollution and catalyst recycling difficulties.

To overcome these disadvantages, varieties of heterogeneous solid acid catalysts, such as molecular sieves, ${ }^{\mathbf{1 4 - 2 1}}$ cation-exchange resins, ${ }^{22,23}$ and carbon-based solid acids, ${ }^{\mathbf{2 4 , 2 5}}$ have been applied as alternative catalysts for the FFAs esterification. Among them, the sulfonated carbon-based catalysts ${ }^{26,27}$ are considered as the promising replacement for the liquid catalysts.

Recently, the ordered mesoporous carbon materials (OMC) have been widely studied. ${ }^{28}$ The typical strategy applied to prepare OMC involves the use of hard templates, such as SBA$15,{ }^{29}$ KIT- $6{ }^{30,31}$ and MCM-48, ${ }^{29}$ with the purpose to obtain 2Dhexagonally packed mesopores or 3D-interconnected mesostructure for widely application.

Currently, the $-\mathrm{SO}_{3} \mathrm{H}$ groups have been introduced to $\mathrm{OMC}$ materials with template SBA-15 by Peng et al. ${ }^{32}$ successfully, which could show the enhanced activity in the acid-catalyzed esterification of oleic acid with methanol. The sulfonic acid groups functionalized OMC have exhibited a broad application prospect for some large molecule reactions, like esterification reaction, owing to their well-defined pore structure, high specific surface area and inherent surface hydrophobicity. ${ }^{33,34}$ These unique features make the sulfonated OMC be benefit for 
long-chain FFAs molecules to access to their effective surface acidic sites, and inhibit the adsorption of byproduct water.

In this work, we prepared sulfonated ordered mesoporous carbon catalysts with sucrose as carbon precursor, SBA-15 and KIT-6 as hard template, respectively. The influences of sulfonation time, sulfonation temperature and hard template structure type on textual parameters, density of $-\mathrm{SO}_{3} \mathrm{H}$ groups, and catalytic activity were systematically studied. Additionally, in order to explore the effects of pore structure and surface property of catalyst on catalytic activity for FFAs esterification, the macroporous cation-exchange resin and amorphous porous carbon-based solid acid, which used the same carbon precursor and preparation conditions as the OMC materials, were evaluated. Besides, the stability of the catalyst and the reason of the catalyst deactivation had also been investigated.

\section{Experimental}

\subsection{Materials}

Pluronic $\mathrm{P} 123\left(\mathrm{EO}_{20} \mathrm{PO}_{70} \mathrm{EO}_{20}\right)$ and tetraethoxysilane (TEOS) were purchased from Sigma-Aldrich Corporation, USA. Other chemical reagents were purchased from Guangfu Chemical Corporation, China. All chemical reagents were analytical grade and directly used without any further purification.

\subsection{General synthesis procedures of mesoporous silica templates}

Two types of mesoporous silica materials (i.e. SBA-15 and KIT-6 zeolites) were employed for the preparation of the OMC. The mesoporous SBA-15 silica zeolite was synthesized according to the procedure reported by Zhao et al., ${ }^{35}$ while KIT-6 mesoporous silica zeolite was prepared by the procedure described by Kleitz et $a .^{31}$

\subsection{Preparation of sulfonated mesoporous carbon catalyst samples}

The synthesis of OMC was performed by means of nanocasting. ${ }^{36}$ Two different templates were used, i.e. SBA-15 zeolite and KIT-6 zeolite. The mesoporous silica zeolite was impregnated with sucrose as the carbon precursor, and then carbonized under $\mathrm{N}_{2}$ atmosphere at $600{ }^{\circ} \mathrm{C}$. The resultant carbon-silica composites were immersed in $48 \% \mathrm{HF}$ aqueous solution at room temperature to remove the silica template completely. The OMC materials were obtained after filtration, washing and drying.

The preparation of sulfonated OMC was carried out under $\mathrm{N}_{2}$ atmosphere protection. Initially, $0.5 \mathrm{~g}$ OMC was added into a PTFE-lined stainless steel hydrothermal autoclave containing $20 \mathrm{~mL}$ of concentrated sulfuric acid (98\%). The mixtures were heated at heating rate of $5{ }^{\circ} \mathrm{C} \min ^{-1}$ to $120-180{ }^{\circ} \mathrm{C}$ for $2-8 \mathrm{~h}$. The samples were washed repeatedly with distilled water, and then dried in a vacuum oven at $60{ }^{\circ} \mathrm{C}$ for $8 \mathrm{~h}$. The sulfonated OMC samples thus obtained were labeled as $\mathrm{SO}_{3} \mathrm{H}-\mathrm{OMC}(\mathrm{X})-t-T_{\mathrm{s}}$, where $X=s$, k, which were abbreviations for SBA-15 and KIT-6 zeolites, respectively, $t$ was the sulfonation time (h), and $T_{\mathrm{s}}$ was the sulfonation temperature $\left({ }^{\circ} \mathrm{C}\right)$.

\subsection{Preparation of other solid acid catalyst samples}

The sugar-derived solid acid catalysts were prepared by using sucrose as the carbon precursor, and labeled as $\mathrm{SO}_{3} \mathrm{H}-\mathrm{APC}-6$ 160 , where 'APC' was the abbreviation for amorphous porous carbons, 6 denoted the sulfonation time ( $6 \mathrm{~h})$, and ' 160 ' denoted the sulfonation temperature $\left(160^{\circ} \mathrm{C}\right)$. All operating parameters of carbonization and sulfonation were the same as the $\mathrm{SO}_{3} \mathrm{H}$ OMC catalyst samples. The strongly acidic macroporous cation-exchange resin (D072) was also used for the comparison with above prepared sulfonated OMC catalysts.

\subsection{Characterization}

The nitrogen adsorption-desorption measurement was performed on a Micromeritics Tristar 3000 type instrument at the temperature of $-196{ }^{\circ} \mathrm{C}$. The samples were degassed under vacuum at $200{ }^{\circ} \mathrm{C}$ for $12 \mathrm{~h}$ prior to measure. The specific surface area was calculated by Brunauer-Emmett-Teller (BET) method. The pore volume was taken at $P / P_{0}=0.99$ assuming complete pore saturation. Ammonia temperature programmed desorption characterization ( $\mathrm{NH}_{3}$-TPD) was performed on a Micromeritics autochemII 2920 type instrument under a mixed stream composed of $1 \mathrm{v} \% \mathrm{NH}_{3}$ in Ar. The microscopic morphology and mesoporous channel structure of sulfonated mesoporous carbon catalysts were observed from the transmission electron microscopic images (TEM) taken by a FEI Tecnai G2 F20 type instrument operated at $400 \mathrm{kV}$. The identification of surface functional groups was carried out by the Fourier transform infrared (FT-IR) spectra, which were recorded on a Nicolet 6700 type spectrometer with 32 scanning times at $4 \mathrm{~cm}^{-1}$ resolution (from $400 \mathrm{~cm}^{-1}$ to $4000 \mathrm{~cm}^{-1}$ ). The content of strong acidic groups (i.e. $\left.-\mathrm{SO}_{3} \mathrm{H}\right)$ on the catalyst surface was measured by the alkaline neutralization titration. ${ }^{37}$ The density measurement procedure for strong acidic groups was as follows: $0.1 \mathrm{~g}$ pre-dried catalyst sample and $1 \mathrm{~g}$ NaCl were dispersed in $30 \mathrm{~mL}$ deionized water. The suspensions were stirred for $2 \mathrm{~h}$ and filtered, then the filtrate was collected and titrated with $0.1001 \mathrm{M} \mathrm{NaOH}$ standard solution using methyl red indicator. The density of $-\mathrm{SO}_{3} \mathrm{H}$ groups could be calculated by the following formula (1):

$$
D_{-\mathrm{SO}_{3} \mathrm{H}}=0.1001\left(V_{1}-V_{0}\right) / m_{\text {cat }}
$$

where $D_{-\mathrm{SO}_{3} \mathrm{H}}$ was the density of strong acidic groups (mmol $\left.\mathrm{g}^{-1}\right) ; V_{0}$ and $V_{1}$ were the volumetric consumption $(\mathrm{mL})$ of $\mathrm{NaOH}$ standard solution in the blank test and neutralization titration; and $m_{\text {cat }}$ was the mass of catalyst (g).

\subsection{Catalytic performance measurement}

In ordered to explore the effects of textual property and surface property on the catalytic activity of $\mathrm{SO}_{3} \mathrm{H}$-OMC catalyst samples, the comparative research was conducted with two different kinds of solid acid catalyst samples ( $\mathrm{SO}_{3} \mathrm{H}-\mathrm{APC}-6-160$ and D072). The catalytic esterification of free fatty acids (FFAs) with methanol was performed in a three-necked round-bottom flask, which was equipped with reflux condenser, magnetic stirrer and temperature adjustable water bath. In a typical procedure, the 
reaction was carried out at feed molar ratio $9: 1$ of methanol to FFAs, the usage amount of catalysts was of $10 \mathrm{wt} \%$, and then the reaction system was maintained at temperature of $70{ }^{\circ} \mathrm{C}$ with the stirring rate of $800 \mathrm{rpm}$. After reaction proceeded for $6 \mathrm{~h}$, the reaction was terminated and the reactant temperature was cooled to room temperature, and then kept static for $2 \mathrm{~min}$. Subsequently, samples of oil phase were transferred out for the acid value analysis by the titration method, ${ }^{37}$ according to BS EN ISO 660 (National Standard of the People's Republic of China. GB/T5330-2005). The conversion of FFAs was calculated from acid value using formula (2):

$$
\text { FFAs conversion }(\%)=\left(1-\mathrm{AV}_{\mathrm{f}} / \mathrm{AV}_{\mathrm{i}}\right) \times 100 \%
$$

where $\mathrm{AV}_{\mathrm{i}}$ was the initial acid value of the raw oil $(\mathrm{mg} \mathrm{KOH}$ per $\mathrm{g}) ; \mathrm{AV}_{\mathrm{f}}$ was the final acid value of reaction products after the catalytic esterification (mg $\mathrm{KOH}$ per $\mathrm{g}$ ).

Recycling experiments were performed to investigate the stability of the sulfonated OMC catalysts ( $\left.\mathrm{SO}_{3} \mathrm{H}-\mathrm{OMC}(\mathrm{s})-6-160\right)$. At the end of each reutilization cycle (each reaction was $6 \mathrm{~h}$ ), the $\mathrm{SO}_{3} \mathrm{H}-\mathrm{OMC}$ catalysts were filtered out from the reaction mixture, washed with anhydrous ethanol to remove the residual reactants from the catalyst surface, and then dried in vacuum at $100{ }^{\circ} \mathrm{C}$ for $2 \mathrm{~h}$, finally the catalyst samples were stored in a desiccator to insulate water adsorption, and reused in the subsequent reaction runs. To eliminate the effect of the catalyst loss caused by filtration, the usage quantity of catalyst samples was reduced to $90 \%$ of that in previous cycle. To keep the same proportion between reactant and catalyst, the reactant amount should be also adjusted accordingly.

Another recycling experiment was conducted to explore the catalyst deactivation situation. Two experimental schemes were designed. Scheme-1, the $\mathrm{SO}_{3} \mathrm{H}-\mathrm{OMC}(\mathrm{s})-6-160$ catalysts were washed repeatedly with methanol for five times, and then the collected filtrate solution after each filtration was reacted with FFAs without the acidic catalysts; Scheme-2, the $\mathrm{SO}_{3} \mathrm{H}-\mathrm{OMC}(\mathrm{s})-$ 6-160 catalysts were washed repeatedly with FFAs for five times, and then the collected filtrate solution after each filtration was reacted with methanol without acidic catalysts. All other reaction conditions were the same as recycling experiments.

\section{Results and discussion}

3.1 Study on sulfonation conditions of mesoporous carbonbased solid acid catalysts

3.1.1 Effects of sulfonation time on the preparation of sulfonated OMC. The pore structural parameters and the density of $-\mathrm{SO}_{3} \mathrm{H}$ groups of $\mathrm{SO}_{3} \mathrm{H}-\mathrm{OMC}(\mathrm{s})-t-160$ samples modified in different sulfonation time were listed in Table 1. The density of $-\mathrm{SO}_{3} \mathrm{H}$ groups on the $\mathrm{SO}_{3} \mathrm{H}-\mathrm{OMC}(\mathrm{s})-t-160$ catalyst surface increased obviously as the sulfonation time was prolonged from $2 \mathrm{~h}$ to $6 \mathrm{~h}$. The increasing tendency of the density of $-\mathrm{SO}_{3} \mathrm{H}$ group slowed down as time was further prolonged continuously $(6-8 \mathrm{~h})$. Furthermore, the textural parameters indicated that the sulfonation time would not affect the mesostructure, since most of the textural properties were almost remained unchanged. Therefore, $\mathrm{SO}_{3} \mathrm{H}$-OMC samples would be sulfonated for $6 \mathrm{~h}$, which was chosen as the optimal modification time.

3.1.2 Effects of sulfonation temperature on the preparation of sulfonated OMC. The FT-IR spectra of both OMC(s) and $\mathrm{SO}_{3} \mathrm{H}-\mathrm{OMC}(\mathrm{s})-6-T_{\mathrm{s}}$ samples were shown in Fig. 1 . The characteristic stretching vibration absorption peaks of the sulfonic group $-\mathrm{SO}_{3}$ bonds $\left(1035 \mathrm{~cm}^{-1}\right)$ and the $\mathrm{O}=\mathrm{S}=\mathrm{O}$ bonds $\left(1214 \mathrm{~cm}^{-1}\right)$ appeared after the sulfonation treatment, ${ }^{38}$ which might be an evidence for the incorporation of $-\mathrm{SO}_{3} \mathrm{H}$ groups in the catalysts successfully. Additionally, with the sulfonation temperature increased from $120{ }^{\circ} \mathrm{C}$ to $180{ }^{\circ} \mathrm{C}$, the intensity of characteristic absorption peaks for $-\mathrm{SO}_{3} \mathrm{H}$ groups also increased, indicating the promote influence of higher sulfonation temperature on the attachment of $-\mathrm{SO}_{3} \mathrm{H}$ groups on the surface of OMC(s).

Fig. 2 showed the $\mathrm{NH}_{3}$-TPD profiles of $\mathrm{SO}_{3} \mathrm{H}-\mathrm{OMC}(\mathrm{s})-6-T_{\mathrm{s}}$ catalyst samples prepared at the sulfonation temperature from $120{ }^{\circ} \mathrm{C}$ to $180{ }^{\circ} \mathrm{C}$. With the programmed temperature rising from $150{ }^{\circ} \mathrm{C}$ to $550{ }^{\circ} \mathrm{C}$, the broad $\mathrm{NH}_{3}$ desorption peak appeared at around $270{ }^{\circ} \mathrm{C}$, indicating the presence of the medium strong acid sites on the surface of $\mathrm{SO}_{3} \mathrm{H}-\mathrm{OMC}(\mathrm{s})-6-T_{\mathrm{s}}$ samples. As with the rising of sulfonation temperature, the area of $\mathrm{NH}_{3}$-TPD desorption peak increased gradually, suggesting the increase in the number of $-\mathrm{SO}_{3} \mathrm{H}$ groups on surface. And no obvious offsets of $\mathrm{NH}_{3}$-TPD peak were observed, which implied that the sulfonation temperature did not effect on the acidic strength of surface acid sites.

The TEM images were presented in Fig. 3. It was proved that the ordered mesoporous morphology of $\mathrm{SO}_{3} \mathrm{H}-\mathrm{OMC}(\mathrm{s})-6-T_{\mathrm{s}}$ samples was finely maintained at the different sulfonation temperatures of $120{ }^{\circ} \mathrm{C}, 140{ }^{\circ} \mathrm{C}$ and $160{ }^{\circ} \mathrm{C}$. However, the mesoporous framework structure of catalyst samples would be destroyed and collapsed obviously, when sulfonation temperature at $180^{\circ} \mathrm{C}$.

The data on the textural properties, the density of $-\mathrm{SO}_{3} \mathrm{H}$ groups and catalytic activity of $\mathrm{SO}_{3} \mathrm{H}$-OMC catalyst samples prepared at different sulfonation temperature ranging from $120{ }^{\circ} \mathrm{C}$ to $180^{\circ} \mathrm{C}$ were summarized in Table 2 . It could be seen

Table 1 Textural properties and density of $-\mathrm{SO}_{3} \mathrm{H}$ groups of sulfonated $\mathrm{OMC}$ samples prepared at different sulfonation time

\begin{tabular}{|c|c|c|c|c|c|c|c|}
\hline \multirow[b]{2}{*}{ Samples name } & \multicolumn{3}{|c|}{ Specific surface area $\left(\mathrm{m}^{2} \mathrm{~g}^{-1}\right)$} & \multicolumn{3}{|c|}{ Pore volume $\left(\mathrm{cm}^{3} \mathrm{~g}^{-1}\right)$} & \multirow[b]{2}{*}{ Density of $-\mathrm{SO}_{3} \mathrm{H}$ groups $\left(\mathrm{mmol} \mathrm{g}^{-1}\right)$} \\
\hline & $S_{\text {total }}$ & $S_{\text {micro }}$ & $S_{\text {meso }}$ & $V_{\text {total }}$ & $V_{\text {micro }}$ & $V_{\text {meso }}$ & \\
\hline $\mathrm{SO}_{3} \mathrm{H}-\mathrm{OMC}(\mathrm{s})-2-160$ & 542 & 109 & 433 & 0.86 & 0.08 & 0.78 & 2.02 \\
\hline $\mathrm{SO}_{3} \mathrm{H}-\mathrm{OMC}(\mathrm{s})-4-160$ & 541 & 110 & 431 & 0.85 & 0.09 & 0.78 & 2.28 \\
\hline $\mathrm{SO}_{3} \mathrm{H}-\mathrm{OMC}(\mathrm{s})-6-160$ & 537 & 116 & 421 & 0.85 & 0.09 & 0.76 & 2.32 \\
\hline $\mathrm{SO}_{3} \mathrm{H}-\mathrm{OMC}(\mathrm{s})-8-160$ & 532 & 113 & 419 & 0.84 & 0.09 & 0.75 & 2.33 \\
\hline
\end{tabular}




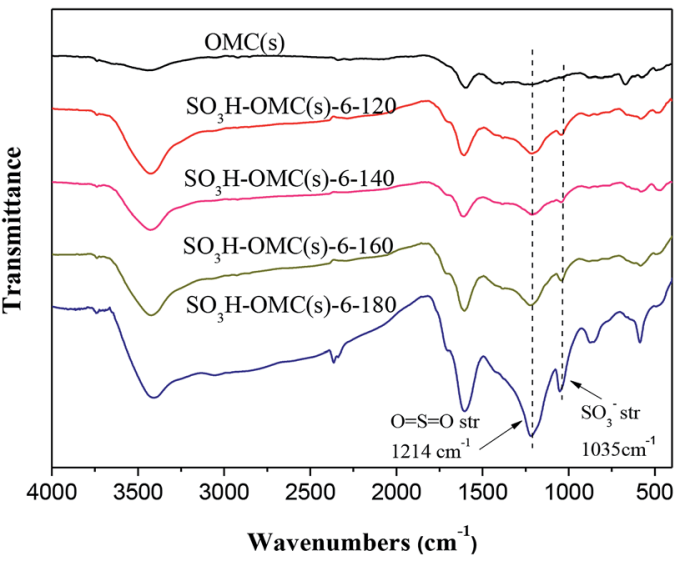

Fig. 1 FT-IR spectra of OMC and sulfonated OMC samples prepared at different sulfonation temperature.

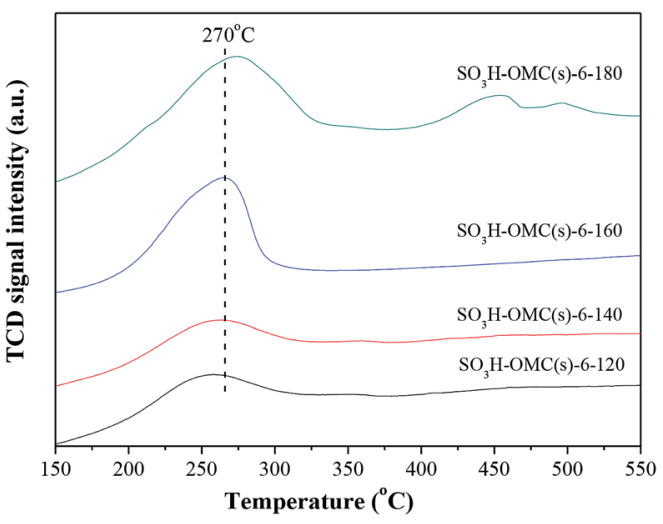

Fig. $2 \mathrm{NH}_{3}$-TPD profiles of sulfonated OMC samples prepared at different sulfonation temperature.

that the acid density of the $\mathrm{SO}_{3} \mathrm{H}-\mathrm{OMC}(\mathrm{s})-6-T_{\mathrm{s}}$ catalysts increased with the rising of sulfonation temperature, which was consistent with the characterization results observed from FTIR spectra and $\mathrm{NH}_{3}$-TPD profiles. When the treatment was at lower sulfonation temperature $\left(120-160^{\circ} \mathrm{C}\right)$, the specific surface area and the pore volume did not change obviously. In this temperature range, with the increasing of sulfonation temperature, the specific surface area and the pore volume of catalyst samples decreased slightly, which might be due to the $-\mathrm{SO}_{3} \mathrm{H}$ groups attached on the surface of OMC samples occupying the pore space. With the treatment at $180{ }^{\circ} \mathrm{C}$, although the $\mathrm{SO}_{3} \mathrm{H}-$ OMC(s)-6-180 sample exhibited the highest density of $-\mathrm{SO}_{3} \mathrm{H}$ groups, the framework of it would be damaged, inducing distinct increase in specific surface area and pore volume, especially microporous specific surface area and pore volume.

\subsection{Catalytic activity evaluations}

3.2.1 Effects of sulfonation temperature on the catalytic activity. From Table 2, all $\mathrm{SO}_{3} \mathrm{H}-\mathrm{OMC}(\mathrm{s})$ samples prepared at different sulfonation temperature exhibited good catalytic performance for the esterification. The catalytic activity of $\mathrm{SO}_{3} \mathrm{H}-\mathrm{OMC}(\mathrm{s})-6-120, \mathrm{SO}_{3} \mathrm{H}-\mathrm{OMC}(\mathrm{s})-6-140$ and $\mathrm{SO}_{3} \mathrm{H}-\mathrm{OMC}(\mathrm{s})-6-$ 160 increased with the increasing temperature, which could be due to the increasing acid density on catalyst surfaces. The $\mathrm{SO}_{3} \mathrm{H}-\mathrm{OMC}(\mathrm{s})-6-160$ catalyst showed the highest catalytic activity with FFAs conversion of $93.8 \%$. Although the $\mathrm{SO}_{3} \mathrm{H}-$ OMC(s)-6-180 catalyst had the highest acid density on surface, its catalytic activity was only $84.3 \%$. Combined with the sulfonation conditions discussed above, it could be concluded that the high catalytic activity of $\mathrm{SO}_{3} \mathrm{H}-\mathrm{OMC}(\mathrm{s})$ catalysts would not only depend on the higher density of $-\mathrm{SO}_{3} \mathrm{H}$ groups on surface, but the rather stable framework structure, which was favorable to the adsorption, diffusion and desorption of the long-chain molecules (e.g. FFAs and FAME), in the reaction system.

3.2.2 Effects of pore structure on the catalytic activity. In order to compare the effects of pore structure on catalytic activity, the catalytic performance of $\mathrm{SO}_{3} \mathrm{H}-\mathrm{APC}-6-160$, D072, $\mathrm{SO}_{3} \mathrm{H}-\mathrm{OMC}(\mathrm{k})-6-160$ and $\mathrm{SO}_{3} \mathrm{H}-\mathrm{OMC}(\mathrm{s})-6-160$ samples for the esterification were investigated. The results of textural properties, density of $-\mathrm{SO}_{3} \mathrm{H}$ groups and catalytic activity were listed in Table 3 and Fig. 4. Compared the textural properties of $\mathrm{SO}_{3} \mathrm{H}-$ APC-6-160 and $\mathrm{SO}_{3} \mathrm{H}-\mathrm{OMC}(\mathrm{X})-6-160$, although the preparation was carried out under the same carbonization and sulfonation conditions, the specific surface area and pore volume of $\mathrm{SO}_{3} \mathrm{H}^{-}$ APC-6-160 sample were lower than those of $\mathrm{SO}_{3} \mathrm{H}-\mathrm{OMC}(\mathrm{X})-6-160$ catalysts. The strong acid density on the surface of $\mathrm{SO}_{3} \mathrm{H}-\mathrm{APC}-6-$ 160 sample was only $1.26 \mathrm{mmol} \mathrm{g}^{-1}$, which might be due to its less specific surface area. Combined with the impacts of specific surface area $\left(34 \mathrm{~m}^{2} \mathrm{~g}^{-1}\right)$ and acid density, the FFAs conversion of $\mathrm{SO}_{3} \mathrm{H}-\mathrm{APC}-6-160$ sample in esterification was only $89.7 \%$.
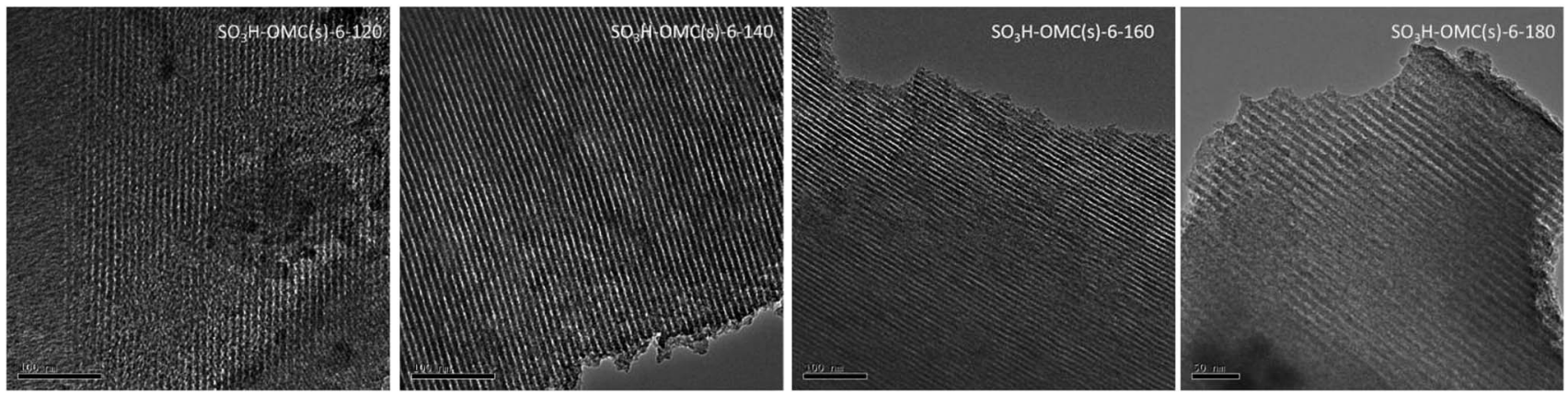

Fig. 3 TEM images of sulfonated OMC samples prepared at different sulfonation temperature. 
Table 2 Textural properties, density of $-\mathrm{SO}_{3} \mathrm{H}$ groups and catalytic activity of sulfonated OMC samples prepared at different sulfonation temperature

\begin{tabular}{|c|c|c|c|c|c|c|c|c|}
\hline \multirow[b]{2}{*}{ Samples name } & \multicolumn{3}{|c|}{$\begin{array}{l}\text { Specific surface } \\
\text { area }\left(\mathrm{m}^{2} \mathrm{~g}^{-1}\right)\end{array}$} & \multicolumn{3}{|c|}{ Pore volume $\left(\mathrm{cm}^{3} \mathrm{~g}^{-1}\right)$} & \multirow{2}{*}{$\begin{array}{l}\text { Density of }-\mathrm{SO}_{3} \mathrm{H} \\
\text { groups }\left(\mathrm{mmol} \mathrm{g}^{-1}\right)\end{array}$} & \multirow[b]{2}{*}{ FFAs conv. (\%) } \\
\hline & $S_{\text {total }}$ & $S_{\text {micro }}$ & $S_{\text {meso }}$ & $V_{\text {total }}$ & $V_{\text {micro }}$ & $V_{\text {meso }}$ & & \\
\hline $\mathrm{SO}_{3} \mathrm{H}-\mathrm{OMC}(\mathrm{s})-6-120$ & 563 & 109 & 454 & 0.89 & 0.08 & 0.81 & 1.92 & 89.6 \\
\hline $\mathrm{SO}_{3} \mathrm{H}-\mathrm{OMC}(\mathrm{s})-6-140$ & 551 & 114 & 437 & 0.88 & 0.09 & 0.79 & 2.07 & 92.3 \\
\hline $\mathrm{SO}_{3} \mathrm{H}-\mathrm{OMC}(\mathrm{s})-6-160$ & 537 & 116 & 421 & 0.85 & 0.09 & 0.76 & 2.32 & 93.8 \\
\hline
\end{tabular}

Table 3 Textural properties, density of $-\mathrm{SO}_{3} \mathrm{H}$ groups and catalytic activity of different solid acid catalysts

\begin{tabular}{|c|c|c|c|c|c|c|c|c|}
\hline Samples name & $S_{\text {total }}$ & $S_{\text {micro }}$ & $S_{\text {meso }}$ & $V_{\text {total }}$ & $V_{\text {micro }}$ & $V_{\text {meso }}$ & $\begin{array}{l}\text { Density of }-\mathrm{SO}_{3} \mathrm{H} \\
\text { groups }\left(\mathrm{mmol} \mathrm{g}^{-1}\right)\end{array}$ & FFAs conv. (\%) \\
\hline $\mathrm{SO}_{3} \mathrm{H}-\mathrm{OMC}(\mathrm{s})-6-160$ & 537 & 116 & 421 & 0.85 & 0.09 & 0.76 & 2.32 & 93.8 \\
\hline $\mathrm{SO}_{3} \mathrm{H}-\mathrm{OMC}(\mathrm{k})-6-160$ & 612 & 138 & 474 & 0.90 & 0.11 & 0.79 & 2.09 & 92.8 \\
\hline $\mathrm{SO}_{3} \mathrm{H}-\mathrm{APC}-6-160$ & 34 & - & - & 0.05 & - & - & 1.26 & 89.7 \\
\hline
\end{tabular}

As shown in Fig. 4, when the esterification was catalyzed by the cation-exchange resin D072, the FFAs conversion was higher than those catalyzed by $\mathrm{SO}_{3} \mathrm{H}-\mathrm{OMC}(\mathrm{s})-160$ catalysts at the initial stage, because its larger pore size would be favorable to the fast diffusion of long-chain FFAs molecules onto the surface acidic active sites. The reaction gradually reached to an equilibrium state with reaction time up to $4 \mathrm{~h}$, and showed a lower FFAs conversion (89.3\%). The relatively low catalytic activity of D072 should be attributed to its poor hydrophobicity. The surface acid active sites were easily combined with the byproduct water and further resulted in the deactivation of parts of the active sites..$^{22,24}$

Compared with both of $\mathrm{SO}_{3} \mathrm{H}-\mathrm{APC}-6-160$ and D072, it could be seen (Fig. 4) that an obvious enhancement of the catalytic performance for the two sulfonated OMC catalyst samples. It was mainly because the effective adsorption of long chain fatty acid molecules could be facilitated in their regular mesoporous channels, ${ }^{39}$ and the acid active sites could be effectively inhibit from byproduct water, owing to the hydrophobicity of OMC surface. .2,33,40 $^{3}$

In addition, the $\mathrm{SO}_{3} \mathrm{H}-\mathrm{OMC}(\mathrm{s})$ and $\mathrm{SO}_{3} \mathrm{H}-\mathrm{OMC}(\mathrm{k})$ samples were prepared by hard template SBA-15 and KIT-6, respectively. It could be also seen from Table 3 and Fig. 4 that, although with a lower density of $-\mathrm{SO}_{3} \mathrm{H}$ groups, the FFAs conversion catalyzed by $\mathrm{SO}_{3} \mathrm{H}-\mathrm{OMC}(\mathrm{k})-6-160$ was higher than that catalyzed by $\mathrm{SO}_{3} \mathrm{H}-$ OMC(s)-6-160 at the initial stage. This phenomenon could be attributed to their difference in special mesoporous structure. The $\mathrm{SO}_{3} \mathrm{H}-\mathrm{OMC}(\mathrm{k})-6-160$ catalyst sample had 3D-cubic arrangement of branched rods, ${ }^{31}$ which could provide abundant diffusion channels and higher specific surface area for the adsorption of reactant molecules (as shown in Table 3), and thus its catalytic activity was higher at the initial stage of esterification. When the reaction time increased to $4 \mathrm{~h}$, the catalytic activity of the $\mathrm{SO}_{3} \mathrm{H}-\mathrm{OMC}(\mathrm{k})-6-160$ sample would be exceeded by the $\mathrm{SO}_{3} \mathrm{H}-\mathrm{OMC}(\mathrm{s})-6-160$ sample gradually. It would be explained that the large organic molecules, such as free fatty acid methyl ester and FFAs, were inclined to stagger together and then block the intersection of the 3D channel, preventing the smoothly diffusion of the reactants and products. The enhancement in catalytic performance of the $\mathrm{SO}_{3} \mathrm{H}-\mathrm{OMC}(\mathrm{s})-6$ 160 sample at this stage could be attributed to its higher density of $-\mathrm{SO}_{3} \mathrm{H}$ groups and the aligned mesoporous channels (2D-hexagonal), which could favor the diffusion of larger organic molecules, and were difficultly blocked.

3.2.3 Comparison of different esterification catalysts. The data on catalytic evaluation of different catalysts for esterification of FFAs and alcohols were summarized in Table S1. $\dagger$ It could be seen that, as the homogeneous catalyst, sulfuric acid exhibited high catalytic activity; ${ }^{\mathbf{4 1}}$ although the FFAs conversion reached $90.0 \%$ of $\mathrm{Pb}$ stearate (a sort of carboxylic salt), it needed severe reaction conditions. $^{\mathbf{4 2}}$ Among the heterogeneous

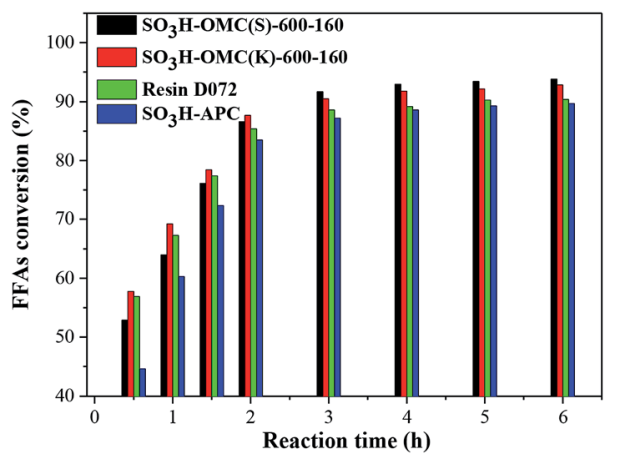

Fig. 4 Catalytic performance of different catalysts for FFAs esterification. 
Table 4 Textural properties, density of $-\mathrm{SO}_{3} \mathrm{H}$ groups and catalytic activity of reused $\mathrm{SO}_{3} \mathrm{H}-\mathrm{OMC}(\mathrm{s})-6-160$ catalyst samples

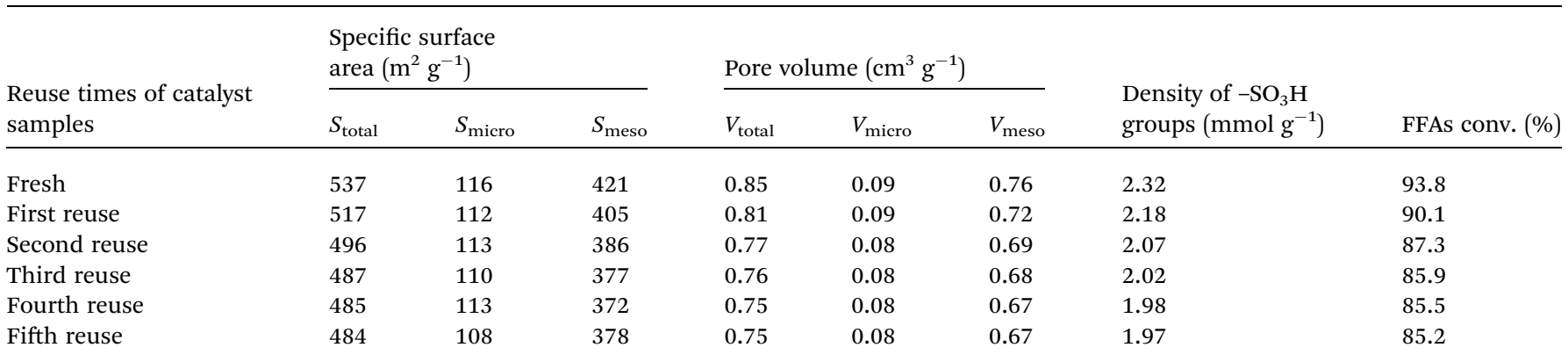

catalysts, macroporous resin Relite CFS exhibited low catalytic performance (FFAs conversion was $74.0 \%$ ). ${ }^{23}$ As one kind of amorphous porous carbon-based solid acid, compared to sucrose carbon-based solid acid $\mathrm{SO}_{3} \mathrm{H}-\mathrm{APC}-6-160$ in this paper, the bagasse carbon-based solid acid catalyst by Zhang et al. ${ }^{43}$ could show better catalytic activity, which FFAs conversion reached $91.4 \%$ at $66{ }^{\circ} \mathrm{C}$ for 4 hours. The catalytic activity of two kinds of ordered mesoporous carbon-based solid acid was listed in Table S1 $\dagger$ as well. Liu et al. ${ }^{34}$ had reported that ethanol could

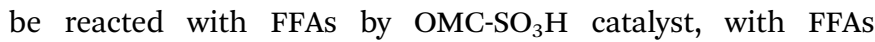
conversion of $73.6 \%$. The $\mathrm{SO}_{3} \mathrm{H}-\mathrm{OMC}(\mathrm{s})-6-160$ catalyst exhibited the highest FFAs conversion in the esterification reaction between methanol and FFAs in a mild reaction condition, which was $93.8 \%$ at $70{ }^{\circ} \mathrm{C}$ for 6 hours.

These results could be attributed to the advantages of the $\mathrm{SO}_{3} \mathrm{H}-\mathrm{OMC}(\mathrm{s})$ catalyst as follows: (a) Compared with the homogeneous catalysts, the $\mathrm{SO}_{3} \mathrm{H}-\mathrm{OMC}(\mathrm{s})$ catalyst of lower corrosion was easy to reuse. (b) Compared with strongly acidic resins, the $\mathrm{SO}_{3} \mathrm{H}-\mathrm{OMC}(\mathrm{s})$ catalyst with hydrophobic surface would effectively prevent the catalyst deactivation caused by the hydration of acid sites on catalyst surface with byproduct water. (c) Compared with amorphous porous carbon-based solid acid catalysts, the $\mathrm{SO}_{3} \mathrm{H}-\mathrm{OMC}(\mathrm{s})$ catalyst with larger specific surface area and higher acid density had ordered and aligned 2Dhexagonal channels, which were favorable for adsorption and diffusion of long-chain molecules.

\subsection{Investigation on catalyst deactivation}

A series of esterification recycling tests were carried out to evaluate the stability of $\mathrm{SO}_{3} \mathrm{H}-\mathrm{OMC}(\mathrm{s})-6-160$ catalyst, and the results were shown in Table 4. The FFAs conversion was gradually decreased from $93.8 \%$ to $87.3 \%$ during the first three use cycles, and then remained almost constant ( $c a$. 85\%) for the next three reuse cycles. According to Fig. S1, $\dagger$ it could be seen that the density of $-\mathrm{SO}_{3} \mathrm{H}$ groups had a strong linear relationship with the FFAs conversion. And the deactivation of FFAs esterification might be due either to the loss of surface acidic activity sites or to the parts of channel blockage by large molecules during the reaction.

In order to explore the reasons for catalyst deactivation, the data on textural properties and the density of $-\mathrm{SO}_{3} \mathrm{H}$ groups attached on the surface of reused $\mathrm{SO}_{3} \mathrm{H}-\mathrm{OMC}(\mathrm{s})-6-160$ catalysts were measured and the results were listed in Table 4. After reused six times, it could be observed that, the microporous specific surface area changed slightly, and the mesoporous specific surface area of $\mathrm{SO}_{3} \mathrm{H}-\mathrm{OMC}(\mathrm{s})-6-160$ catalyst was decreased by $50 \mathrm{~m}^{2} \mathrm{~g}^{-1}$, probably due to the plugging of mesopores. Additionally, the trend of the density of $-\mathrm{SO}_{3} \mathrm{H}$ groups on surface was much in agreement with that of FFAs conversion in the catalytic performance, suggesting the loss of the surface $-\mathrm{SO}_{3} \mathrm{H}$ groups could result in the deactivation of catalysts.

Fig. 5 showed the catalytic esterification activity between reactants and solution obtained from washing catalysts, using the method of Scheme-1 and Scheme-2 described in 2.6 Section. As could be seen from Fig. 5, the esterification between methanol and FFAs could proceed self-catalysis (with FFAs conversion of $15.7 \%$ ). It was obvious that the FFAs conversions of two schemes were much higher than that of spontaneous esterification reaction, which suggested that of the partial active $-\mathrm{SO}_{3} \mathrm{H}$ groups on the catalyst surface were leached out, and dissolved in the washing solvent during agitation and immersion. The FFAs conversion comparison of Scheme- 1 and Scheme- 2 to selfcatalysis esterification reaction could reflect the catalytic activity of the $-\mathrm{SO}_{3} \mathrm{H}$ groups which were dissolved in methanol and FFAs as washing solvent, respectively. On the fifth usage, the catalytic activities of the two schemes were close the spontaneous esterification reaction, suggesting no additional losing of $-\mathrm{SO}_{3} \mathrm{H}$ groups from the surface of the $\mathrm{SO}_{3} \mathrm{H}-\mathrm{OMC}(\mathrm{s})-6-160$ catalyst sample.

In this work, the catalytic activity of losing $-\mathrm{SO}_{3} \mathrm{H}$ groups could be the summation of catalytic activities of the $-\mathrm{SO}_{3} \mathrm{H}$ groups dissolved in above two different kinds of washing solvent. And the decline value of catalytic activity in Table 4

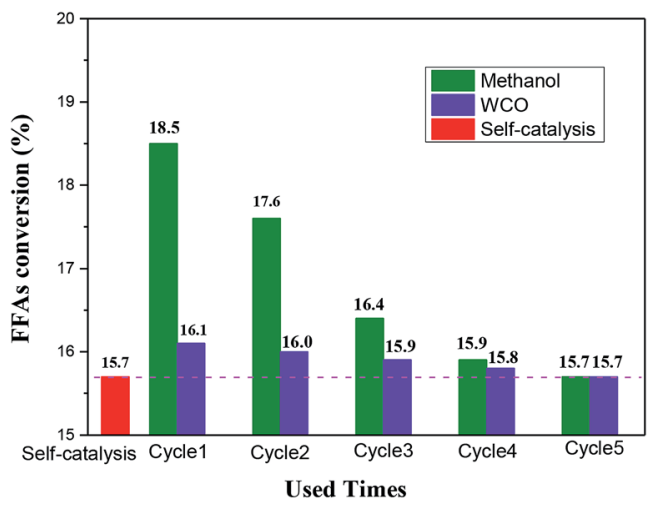

Fig. 5 Catalytic esterification activity between reactants and solution obtained from washing catalyst. 


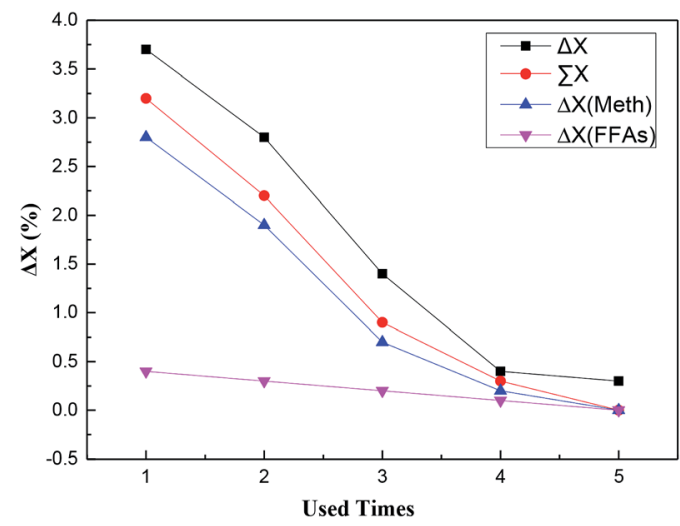

Fig. 6 Deactivation analysis of $\mathrm{SO}_{3} \mathrm{H}-\mathrm{OMC}(\mathrm{s})-6-160$ catalyst sample $\Delta X$ (FFAs): the difference between adjacent FFAs conversion catalyzed by the $-\mathrm{SO}_{3} \mathrm{H}$ groups dissolved in FFAs as washing solvent; $\Delta X$ (Meth): the difference between adjacent FFAs conversion catalyzed by the $-\mathrm{SO}_{3} \mathrm{H}$ groups dissolved in methanol as washing solvent; $\sum X$ : FFAs conversion catalyzed by the $-\mathrm{SO}_{3} \mathrm{H}$ groups dissolved in the two different kinds of washing solvent; $\Delta X$ : the difference between adjacent FFAs conversions in Table 4.

could be denoted by the difference between adjacent FFAs conversions (labeled as $\Delta X$ in Fig. 6).

As demonstrated in Fig. 6, with the usage times increasing, the catalytic activity of losing $-\mathrm{SO}_{3} \mathrm{H}$ groups decreased gradually until disappeared completely, which indicated the decreased amount of $-\mathrm{SO}_{3} \mathrm{H}$ groups leached out from the catalyst surfaces into the reaction solvent. Additionally, with the same usage time, the difference was very small when comparing the catalytic activity of the losing $-\mathrm{SO}_{3} \mathrm{H}$ groups with the decline value of the catalytic activity, and the latter was slightly larger than the former (shown in Fig. 6). Hence, it could be concluded that the loss of surface active sites $\left(-\mathrm{SO}_{3} \mathrm{H}\right.$ groups) should mainly result in the catalyst deactivation in the esterification, affecting the activity and stability of catalysts.

Fig. 6 also showed that the catalytic activity of Scheme-1 was considerably higher than that of Scheme-2, accounting for a larger proportion in the catalytic activity of the losing $-\mathrm{SO}_{3} \mathrm{H}$ groups. The reason that aroused above-mentioned phenomenon could be partially attributed to the different usage amount of the solvents (molar ratio of methanol to FFAs was $9: 1$ ). More importantly, due to the stronger polarity of methanol than oils and fatty acids, the methanol as solvent could easily promote the formation of a local polar environment, ${ }^{19}$ resulting in the $-\mathrm{SO}_{3} \mathrm{H}$ groups being leached out of catalysts and the decrease of the catalytic activity.

\section{Conclusions}

In this work, sulfonated ordered mesoporous carbon $\left(\mathrm{SO}_{3} \mathrm{H}^{-}\right.$ OMC) solid acid catalysts with high density of $-\mathrm{SO}_{3} \mathrm{H}$ groups were obtained at the sulfonation time of $6 \mathrm{~h}$ and the sulfonation temperature of $160^{\circ} \mathrm{C}$. Compared to the sulfonated amorphous porous carbon-based solid acid catalyst and the cationexchange resin $\mathrm{D} 072$, the $\mathrm{SO}_{3} \mathrm{H}-\mathrm{OMC}$ catalysts exhibited relatively high activity for the FFAs esterification (FFAs conversion was $93.8 \%$ ), which could be attributed to its high specific surface area, regular mesoporous channels and hydrophobic surface. The $\mathrm{SO}_{3} \mathrm{H}-\mathrm{OMC}(\mathrm{s})$ catalyst with $2 \mathrm{D}$-hexagonal channels exhibited a higher catalytic activity than the $\mathrm{SO}_{3} \mathrm{H}-\mathrm{OMC}(\mathrm{k})$ catalyst with 3D-interconnected channels, attributed to its aligned pore structure which could favour large molecular diffusion and prevent channel blockage. Through series of deactivation experiments and analysis, it was found that, the $-\mathrm{SO}_{3} \mathrm{H}$ groups being leached out of $\mathrm{SO}_{3} \mathrm{H}-\mathrm{OMC}$ catalysts into the liquids (especially into the reactant methanol with stronger polarity) would be the main reason causing catalyst deactivation during the FFAs esterification.

\section{Conflicts of interest}

There are no conflicts to declare.

\section{Acknowledgements}

The authors are grateful for the financial support from the Natural Science Foundation of China (No. 21104035).

\section{References}

1 F. R. Ma and M. A. Hanna, Bioresour. Technol., 1999, 70, 1-15. 2 N. Yusuf, S. K. Kamarudin and Z. Yaakub, Energy Convers. Manage., 2011, 52, 2741-2751.

3 P. S. Nigam and A. Singh, Prog. Energy Combust. Sci., 2011, 37, 52-68.

4 M. J. Niu and X. J. Kong, RSC Adv., 2015, 5, 27273-27277.

5 G. P. Hammond, S. Kallu and M. C. McManus, Appl. Energy, 2008, 85, 506-515.

6 S. K. M. Rozi, S. Bakhshaei, N. S. A. Manan and S. Mohamad, RSC Adv., 2016, 6, 87719-87729.

7 J. Yan, Appl. Energy, 2009, 86, S1-S10.

8 A. N. Phan and M. P. Tan, Fuel, 2008, 87, 3490-3496.

9 M. A. M. Ali, R. M. Yunus, C. K. Cheng and J. Gimbun, RSC Adv., 2015, 5, 76743-76751.

10 M. Canakci, Bioresour. Technol., 2007, 98, 183-190.

11 S. Semwal and A. K. Arora, Bioresour. Technol., 2011, 102, 2151-2161.

12 L. T. Wang, X. Q. Dong, H. X. Jiang, G. M. Li and M. H. Zhang, Fuel Process. Technol., 2014, 128, 10-16.

13 L. T. Wang, X. Q. Dong, H. X. Jiang, G. M. Li and M. H. Zhang, Catal. Commun., 2014, 56, 164-167.

14 A. A. Costa, P. R. S. Braga, J. L. de Macedo, J. A. Dias and S. C. L. Dias, Microporous Mesoporous Mater., 2012, 147, 142-148.

15 K. H. Chung and B. G. Park, J. Ind. Eng. Chem., 2009, 15, 388392.

16 S. Ajaikumar and A. Pandurangan, J. Mol. Catal. A: Chem., 2007, 266, 1-10.

17 J. K. Satyarthi, D. Srinivas and P. Ratnasamy, Energy Fuels, 2010, 24, 2154-2161.

18 J. A. Melero, L. F. Bautista, G. Morales, J. Iglesias and R. Sanchez-Vazquez, Chem. Eng. J., 2010, 161, 323-331.

19 D. H. Zuo, J. Lane, D. Culy, M. Schultz, A. Pullar and M. Waxman, Appl. Catal., B, 2013, 129, 342-350. 
20 C. Pirez, J. M. Caderon, J. P. Dacquin, A. F. Lee and K. Wilson, ACS Catal., 2012, 2, 1607-1614.

21 I. K. Mbaraka and B. H. Shanks, J. Catal., 2005, 229, 365-373.

22 J. Y. Park, Z. M. Wang, D. K. Kim and J. S. Lee, Renewable Energy, 2010, 35, 614-618.

23 R. Tesser, M. D. Serio, L. Casale, L. Sannino, M. Ledda and E. Santacesaria, Chem. Eng. J., 2010, 161, 212-222.

24 L. T. Wang, X. Q. Dong, H. X. Jiang, G. M. Li and M. H. Zhang, Bioresour. Technol., 2014, 158, 392-395.

25 T. Masakazu, T. Atsushi, O. Mai, J. N. Kondo, H. Shigenobu, D. Kazunari and H. Michikazu, Nature, 2005, 438, 178.

26 W. Y. Lou, M. H. Zong and Z. Q. Duan, Bioresour. Technol., 2008, 99, 8752-8758.

27 J. A. Maciá-Agulló, M. Sevilla, M. A. Diez and A. B. Fuertes, Chemsuschem, 2010, 3, 1352-1354.

28 W. Xin and Y. H. Song, RSC Adv., 2015, 5, 83239-83285.

29 S. Jarczewski, M. Drozdek, P. Michorczyk, C. CuadradoCollados, J. Gandara-Loe, J. Silvestre-Albero and P. Kuśtrowski, Microporous Mesoporous Mater., 2018, 271, 262-272.

30 V. Duraisamy, S. Palanivel, R. Thangamuthu and S. M. S. Kumar, ChemistrySelect, 2018, 3, 11864-11874.

31 F. Kleitz, S. H. Choi and R. Ryoo, Chem. Commun., 2003, 9, 2136-2137.

32 L. Peng, A. Philippaerts, X. X. Ke, J. Van Noyen, F. De Clippel, G. Van Tendeloo, P. A. Jacobs and B. F. Sels, Catal. Today, 2010, 150, 140-146.
33 X. Q. Wang, R. Liu, M. M. Waje, Z. W. Chen, Y. S. Yan, K. N. Bozhilov and P. Y. Feng, Chem. Mater., 2007, 19, 2395-2397.

34 R. Liu, X. Q. Wang, X. Zhao and P. Y. Feng, Carbon, 2008, 46, 1664-1669.

35 D. Zhao, J. Feng, Q. Huo, N. Melosh, G. H. Fredrickson, B. F. Chmelka and G. D. Stucky, Science, 1998, 279, 548-552.

36 C. Yu, J. Fan, B. Tian, D. Zhao and G. D. Stucky, Adv. Mater., 2010, 14, 1742-1745.

37 B. Chang, F. Jie, Y. Tian and X. Dong, Appl. Catal., A, 2012, 437-438, 149-154.

38 S. Satoshi, N. Kiyotaka, K. Masaaki, Y. Daizo, K. Hideki, H. Shigenobu and H. Michikazu, J. Am. Chem. Soc., 2008, 130, 12787-12793.

39 X. Q. Dong, Y. Jiang, W. B. Shan and M. H. Zhang, RSC Adv., 2016, 6, 17118-17124.

40 F. J. Liu, K. Huang, A. M. Zheng, F. S. Xiao and S. Dai, ACS Catal., 2018, 8, 372-391.

41 A. A. Kiss, F. Omota, A. C. Dimian and G. Rothenberg, Top. Catal., 2006, 40, 141-150.

42 M. Di Serio, R. Tesser, M. Dimiccoli, F. Cammarota, M. Nastasi and E. Santacesaria, J. Mol. Catal. A: Chem., 2005, 239, 111-115.

43 M. H. Zhang, A. X. Sun, Y. L. Meng, L. T. Wang, H. X. Jiang and G. M. Li, Catal. Surv. Asia, 2015, 19, 61-67. 